One of the delights of the book is the sense one gets when reading, of engaging in debate with the 'group' of voices present. This is a virtual kind of debate, which shifts with each short, sharp encounter. An excellent example of where two chapters argue directly with each other is in Section 3 'Inclusion \& Exclusion', with the juxtaposition of Sreedhar and Hand's 'The Ethics of Exclusion: Gender and Politics at the Michigan Womyn's Music Festival' and Niki's 'Women's Spaces are Not Trans Spaces: Maintaining Boundaries of Respect'.

The former contains a provocative call to exclude trans women from buildings, services (such as a rape crisis centre), and spaces set up for women because of, for example, rape survivors' potential 'terror at the presence and display of a penis' ( $p .156$ ), and is called to account by a perspective in the latter that would rather move to a self-identification model when categorizing woman: ' $[W]$ omanhood is a constellation of anatomical, psychological, experiential and phenomenological properties, none of which is even arguably necessary or sufficient for womanhood' (Sreedhar and Hand, p. 166). This for me is one of the clearest and most straightforward (and at the same time, beautifully paradoxical) statements in the collection and one that supports Scott-Dixon's opening call to reveal social structures and environments as being the things that present obstacles to an equitable lived experience for all, rather than individuals being the 'problem'.

Catherine McNamara

doi: $10.1057 /$ fr. 2008.28

\title{
Tackling the roots of racism: lessons for success
}

Reena Bhavnani, Heidi Safia Mirza and Veena Meetoo, in association with the Joseph Rowntree Foundation; Policy Press, Bristol, UK, 2005, 230pp., ISBN 1-861-3477-4X, £15.99 pbk

Thirty years on from the Race Relations Act, racism remains alarmingly rife in British society, and the complexities of race and racism are still areas that command serious debate. Despite these complexities, scholars observe the often formulaic and tokenistic thinking, and misguided oversimplification that often accompanies such debates. During the years since the Race Relations Act, Britain has seen the emergence of a plethora of policies, procedures and initiatives proposing strategies for the reduction of racism. However, as the authors astutely observe there has been little research conducted to examine whether the results of such initiatives have lived up to prior expectations. While many 
interventions are produced, few actually address the underlying causes of racism, and many can be seen as a simple attempt to satisfy legislation, meet targets, or as a sticking plaster to remedy the effects of racism rather than targeting the root causes. It is these issues to which this book is devoted.

Supported by the Joseph Rowntree Foundation, this book aims to review evidence of the success of current and previous interventions to tackle racism both in Britain and abroad. The authors have explored a wide range of disciplines in their review of relevant literature, including anthropology, psychology and sociology, and they have made use of primary documents belonging to individuals and organizations. Significant findings of this book suggest that a lack of clarity on what racism actually 'is', an overemphasis on quantifiable outcomes, and a misreading of evidence showing a decline in racism, often create barriers to real progress in tackling root causes. The authors recommend three themes for consideration when shaping future interventions: education as a means for preventing and unlearning racism; the role of communication in opening crossracial dialogue and developing relationships; and vigilance in the monitoring and exposing of 'the invisible racist elite' often central to the reproduction of racism.

Chapter 1 provides an excellent starting point for the book by supplying definitions for relevant terminology and describing a history of the changing face of racism, particularly exploring macro and micro racisms. Careful in its explanations, this chapter will prove useful particularly to those new to the field.

Chapter 2 explores the difficulties associated with defining success in the various interventions (including multicultural and equality interventions), and how this is subject to change.

In Chapters 3 and 4 the writers explore 'everyday racisms'. Introducing the concept of 'elite racism' mostly perpetuated by the media and government, clear examples are given showing the prevalence of overt racisms that often go unchallenged, particularly in relation to asylum seekers and the normalization of whiteness. Taking its cue from social psychology, Chapter 4 explores the effect elite racism has regarding the creation of stereotypes, and how this translates to ordinary people. This chapter also emphasizes the need to consider multiple aspects of identity such as gender, class, age, and ability when situating local racisms. These chapters offer a really comprehensive analysis and in language that is accessible to all, they lay the ground work for considering key issues in addressing racism.

Chapter 5 presents antidiscrimination legislation and a critical analysis of the effectiveness of such legislation in combating racism. The authors argue the links between legislation on immigration and race, and produce an eye-opening account of the contradictions that this presents. 
Chapters 6 and 7 investigate the effectiveness of interventions designed to address equality. In examining employment interventions, the authors discover that there is little evidence to suggest that actions such as equality policies, racial harassment procedures or recruitment policies have been appropriately evaluated or shown any evidence of success. The book shows that while much has been done in attempts to improve access to services such as health, housing, education, leisure and justice, few of these address the roots of racism. This chapter should be considered essential reading for service providers.

Chapter 8 looks at multiculturalism. Arguments are clearly presented offering real insight for the reader into the contested debate on multiculturalism and interventions that focus on a recognition of difference and how this relates to the new hot topic 'community cohesion'.

Chapter 9 places all previous chapters in greater context by analysing successful interventions and the reasons for their success. The chapter emphasizes the diversity of approaches that can and must be considered when attempting to tackle multiple racisms. This chapter should prove inspirational to those hoping to produce positive interventions themselves.

Finally, Chapter 10 sums up the underlying causes of racism, its reproduction, and strategies for challenging them.

The appendices that accompany this book contain a compendium of successful interventions, a useful and comprehensive list of race-related legislation spanning the last two centuries, and a glossary of terms, thus ensuring the accessibility of this book to those perhaps just starting out in this field.

The concise description of policy interventions, accompanied by the authors' perceptive analysis of their outcomes, ensure that this book is an important text for academics, researchers and students of social science. This book should also be regarded as essential for service providers and policy makers hoping to improve race equality and utilize lessons learned to combat racism.

doi: $10.1057 / \mathrm{fr} .2008 .27$

Laura Green 